\title{
viewpoint
}

\section{Of plants and people}

\author{
Why do we care about dignity?
}

\section{Shawn H.E. Harmon}

$\mathrm{R}$ eferences to human dignity are littered throughout modern human rights and bioethics instruments, from the Universal Declaration of Human Rights (1948) and the European Convention on Human Rights (1950), to UNESCO's Universal Declaration on Bioethics and Human Rights (2005) and the latest version of the Declaration of Helsinki (2008). Dignity is both the background value of these texts, and the primary principle upon which they are constructed.

\section{Ultimately, the value of dignity is in the eye of the beholder; it depends on their interpretation and sociopolitical objective}

Despite this ubiquitous reliance on dignity, it remains a notoriously slippery concept; it can be either a positive and empowering value, or a negative and constraining one (Harmon, 2008). Here, I define 'values' as deeply held ideas or moral concepts about what is good and right-which are constitutive of the selfand what supports human flourishing and contributes both to personal and to social identity-which are the tenets of justice. In both cases, values are complex, overlapping and opaque, and therefore often hidden. I define 'principles' in much the same way, but with one subtle difference: values are more social, idealistic and of a higher order than principles, which are more legally grounded and instrumental.

Ultimately, the value of dignity is in the eye of the beholder; it depends on their interpretation and sociopolitical objective. In short, although dignity is intuitively comprehensible and universally appealing-no one wants to be said to act against dignityit is also confounding and contentious, and, as such, its utility as an action-guiding tool has been questioned (Macklin, 2003; Harmon, 2005).

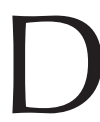
espite the fact that dignity is a rather opaque concept, it persists as a pillar in the legal realm. The first article of the German Constitution, for example, states that, "Human dignity shall be inviolable. To respect and protect it shall be the duty of all state authority." Similarly, Article 7 of the Swiss Constitution says, "Human dignity is to be respected and protected." Legislators, both national and international, continue to rely on dignity in governing instruments in biotechnology and other fields, and thereby impose on stakeholders the necessity of demonstrating compliance, at least notionally, with dignity in the pursuit of their work. The Swiss have gone further than most in this regard. More than a decade ago, the Swiss Constitution was amended to include a provision stipulating that account must be taken of the dignity of creation when handling animals, plants and other organisms. This led to the Gene Technology Act 2004 in Switzerland, which states that the dignity of creatures-animals, plants and other life forms-should be considered in any research.

The Act allows-indeed encouragesrules and regulations to be based on dignity for both humans and non-human species. This state of affairs prompted the Swiss Ethics Committee on Non-Human Biotechnology $(\mathrm{ECNH})$ to conclude, by a majority, that living organisms, including plants, have their own inherent worth, and, as such, should not be used frivolously or "simply as we please" (ECNH, 2008).
One consequence is that researchers in Switzerland must now include a paragraph in their funding applications that addresses how they have considered plant or animal dignity in formulating their protocols. Not surprisingly, nobody really knows what plant dignity is, and the law has been accused of being unreasonable and incompatible with any form of basic research in that it imposes on researchers the need to identify immediate benefits from any research project that uses plants or animals (Abbott, 2008a; Haines, 2008).

\section{If dignity is so important, why do we ignore it and often actively circumvent it even when dealing with fellow humans?}

The difficulty with complying with the law and the uncertainty surrounding its requirements can be seen in an ongoing case concerning neuroinformatics research using rhesus monkeys-approved by the Swiss National Science Foundation and the Zurich Veterinary Office in 2006. The Swiss Advisory Committee on Animal Experimentation appealed against the issuance of the research licenses and, in 2007, the local court upheld the appeal, banning the experiments, in part on the basis of monkeys' dignity. The University of Zurich and the Federal Institute of Technology in Zurich appealed the decision to the canton's administrative court but, in 2008, their appeal was refused.

$\mathrm{S}$ imilar to many other observers of the social and legal aspects of the biosciences (Sandberg, 2008; Smith, 2008), I thought that both this law and its 
fallout were faintly ridiculous, and probably another example of a law with good intentions applied in a manner in which it was never intended. Reports that debates had arisen over the indignity visited upon wild flowers by their 'decapitation' fortified that reaction (Abbott, 2008b). Given that we raze forests to raise livestock and plough pastures to plant biofuels for gas-guzzling SUVs, I thought it unseemly, even absurd, to debate seriously the 'dignity' of plants that are being used in the laboratory.

As noted above, dignity is an amorphous concept that is used to support almost any position one might wish to take on almost any issue in medical research or social analysis; most often it is intended to enhance the individual's integrity and the respect accorded to them, but it is variously interpreted, selectively applied and unevenly enjoyed. If dignity is so important, why do we ignore it and often actively circumvent it even when dealing with fellow humans? Leaving aside widely supported actions of government that are specifically designed to diminish dignity, such as jail terms for convicted criminals or physically abusive interrogations of suspects, let us consider the following characteristics of the modern world from a healthcare perspective.

Many people die from neglect or from easily preventable dis-

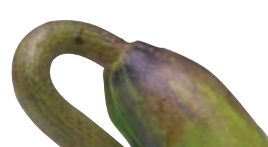
eases without receiving any treatment. The divide between developed and developing countries is still widening, with immense implications for healthcare and the realization of wellbeing. We spend billions of dollars and euros on research that does not address the diseases from which most people on this planet suffer, or that cannot possibly lead to treatments that would be acces- sible to the majority of the world's

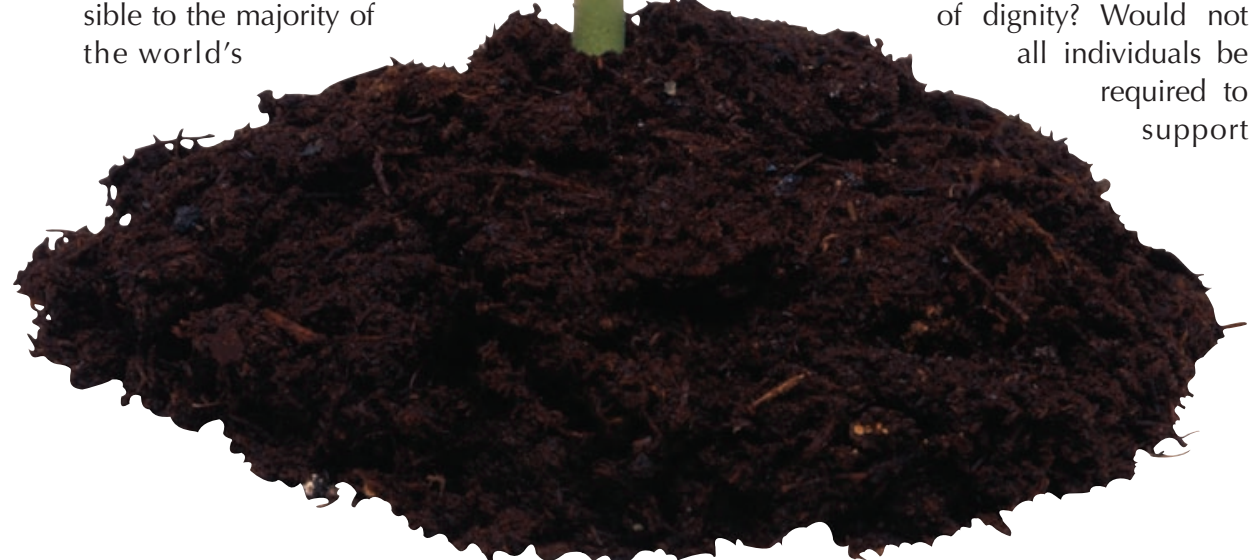
of dignity? Would not all individuals be ired to population in the short, medium or even long term. We persistently degrade the environment in pursuit of commercial interests, although it is well understood that humanand animal and plant-wellbeing is dependent on environmental health. In short, little is done to avoid circumstances in which people or other species languish in the most base of undignified states.

It is obvious, then, that despite our rhetorical attachment to dignity in the human rights and bioethics paradigms, as a global community we are unable to even agree on collective or prescribed responsibility for protecting human dignity, let alone that of other species. Is it the United Nations, the leaders of the richest countries, health ministries, environmental ministries, armed forces or individual citizens who are most responsible for the dignity of others? More often than not, these entities, particularly the last two, facilitate indignity and inhumanity. Individuals, particularly those in the developed world, enjoy massive benefits and have few duties, hardly ever taking seriously a duty to actively promote and enhance the dignity of others or the environment. For evidence of this, we might consider our sporadic, selective and largely ineffectual attempts at aiding those suffering due to persistent food or medical shortages, or social upheaval, and our continued destruction of wilderness and habitats.

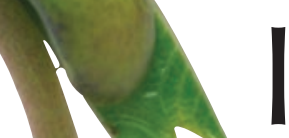

$f$ we accept that dignity is an inherent good-and I believe we do-and if we could agree on what it should be-and I believe we could find a minimum consensusand if we truly cared for all living beings on this planet, including plants, would we not do things differently? Would we not mobilize all societies and their resources towards improving everyone's wellbeing and actually achieving some modicum and contribute to publicly funded research with the aim of finding cures for both rare and common diseases and conditions? But we neither require this of the individual, nor demand such heroic efforts from our public bodies. We cannot even tolerate the idea of acting in this manner because of the 'unthinkable' social and financial upheaval it would necessitate. Is this because dignity is merely the empty rhetorical tool of a liberal ideology gone too far that has conducted a centuries-long campaign against communitarianism? Is it because it is just too difficult to achieve this goal through the institutions with which we have become comfortable? Is it because the formulations and interpretations of dignity that have come to the fore are more about individual autonomy than about the community and the environment?

\section{Perhaps mandating serious consideration of dignity [...] is a first and crucial step in truly realizing this value, which resonates with so many people and societies}

These questions highlight not only the difficulty associated with improving the human lot, but also the difficulty of hoping to do so based on an approach that relies on dignity; we cannot even agree on what dignity demands of us or for us. And now we are demanding that researchers wrestle with the dignity of plants. I am not against critical consideration of such esoteric issues in principle-as higher conscious beings, indeed the beings with the highest consciousness we have recognized so far, it rightfully falls to us to do so-but to do so at the expense of more serious ethical concerns is, I reasoned, a comedy-perhaps a tragedy-worthy of Shakespeare's quill. But, of course, I could be completely wrong.

Perhaps mandating serious consideration of dignity, not only of humans but also of animals and plants, even in the absence of a global consensus, is a first and crucial step in truly realizing this value, which resonates with so many people and societies. Maybe it will force researchers to become more engaged with issues beyond the scientific questions with which they commonly wrestle. Maybe it will force all of us to arrive at some better understanding of what dignity could mean. It has been argued that our senses and cognitive limitations 
hinder our ability to respond rationally to the catastrophic environmental threats we are already facing at the beginning of this century; threats that are largely of our own making (Hanski, 2008; Vince, 2009). Maybe a mandated duty to consider seriously and explicitly the dignity of humans, animals, plants and, ultimately, the environment is a crucial step towards adopting a broader view that will help us to better comprehend and turn positive our enormous impact on the Earth and its other species, thus improving our own future prospects. Maybe the Swiss are to be applauded.

\section{CONFLICT OF INTEREST}

The author declares that they have no conflict of interest.

\section{ACKNOWLEDGEMENTS}

The author thanks Graeme T. Laurie for helpful contributions to this and other works. The author also acknowledges financial support from the UK Economic and Social Research Council.

\section{REFERENCES}

Abbott A (2008a) Swiss 'dignity' law is threat to plant biology. Nature 452: 919

Abbott A (2008b) The use of 'dignity' as the foundation for an ethical law in Switzerland is compromising research. Nature 453: 824

ECNH (2008) The Dignity of Living Beings with Regard to Plants. Bern, Switzerland: Swiss Federal Ethics Committee on Non-Human Biotechnology

Haines L (2008) Swiss ponder the 'dignity of plants'. The Register, May 9. www.theregister.co.uk

Hanski I (2008) The world that became ruined. EMBO Rep 9: S34-S36

Harmon S (2005) Regulation of human genomics and genetic biotechnology: risks, values and analytical criteria. Edinburgh, UK: ESRC Innogen Centre

Harmon S (2008) Ethical rhetoric: genomics and the moral content of UNESCO's 'universal' declarations. J Med Ethics 34: e24

Macklin R (2003) Dignity is a useless concept. BM/ 327: 1419-1420

Sandberg A (2008) The dignity of the carrot. Practical Ethics, April 24

www.practicalethicsnews.com
Smith W (2008) The silent scream of the asparagus: get ready for 'plant rights'. The Weekly Standard, May 12. www.weeklystandard.com

Vince G (2009) Surviving in a warmer world. New Scientist 201: 28-33

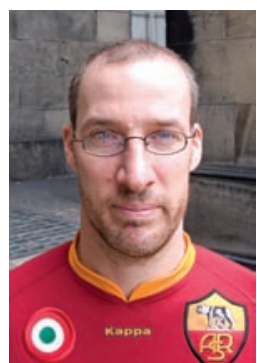

Shawn H.E. Harmon is a research fellow at the ESRC Centre for Social and Economic Research on Innovation in Genomics, University of Edinburgh, UK.

E-mail: shawn.harmon@ed.ac.uk

doi:10.1038/embor.2009.191 